\title{
Assessment in Medical Education; What Are We Trying to Achieve?
}

\author{
Dr Helena Ferris ${ }^{1} \&$ Dermot O ' Flynn ${ }^{2}$ \\ ${ }^{1}$ Lecturer in Clinical Medicine, Trinity College Dublin, Ireland \\ ${ }^{2}$ Director of Professional Development, Institute of Leadership, Royal College of Surgeons, Ireland \\ Correspondence: Dr Helena Ferris, Lecturer in Clinical Medicine, Trinity College Dublin, Ireland. E-mail: \\ ferrish@tcd.ie
}

Received: March 16, 2015

Accepted: March 30, 2015

Online Published: March 31, 2015

doi:10.5430/ijhe.v4n2p139

URL: http://dx.doi.org/10.5430/ijhe.v4n2p139

\begin{abstract}
Within the arena of medical education, it is generally acknowledged that assessment drives learning. Assessment is one of the most significant influences on a student's experience of higher education and improving assessment has a huge impact on the quality of learning (Liu, N. and Carless, D, 2006). Ideally we want to enhance student's capacity for learning and engagement with the curriculum (ACGME Outcome Project, 2000). However, this doesn't always happen as it is heavily dependent on the form of assessment used and whether or not timely comprehensive feedback is given.

This paper focuses on the challenges associated with assessment in medical education and looks at the current trends. Well-designed formative assessment can focus students on effective learning and divert them away from summative assessment, which focuses attention on grades and reproductive thinking (Liu, N. and Carless, D, 2006). Whether one decides to utilise summative or formative assessment methods, both methods of assessment are useful when applied in the correct setting and at an appropriate stage of learning.

It is apparent that assessment is the gatekeeper of higher learning and we need to embrace new methods of assessment in order to meet the challenges associated with 'Generation Y'. Novel assessment methods such as self and peer assessment are growing in popularity. Students who participate in these forms of assessment may initially feel that it is challenging but worthwhile overall, as it helps to develop their critical thinking skills. Incorporating complimentary assessment components could benefit student's learning without sacrificing the integrity of the curriculum.
\end{abstract}

Keywords: Medical education, Assessment, Peer learning, Self-assessment

\section{Introduction}

Within the arena of medical education, it is generally acknowledged that assessment drives learning (Wormald BW, Schoeman S, Somasunderman A et al, 2009). All forms of assessment invariably have inherent strengths and flaws but it is important to consider how the process of assessment might foster future learning (Friedman BDM, 2000). After all, we want to reinforce students' intrinsic motivation to learn and to inspire them to set higher standards for themselves (Epstein R, 2007).

The following paper evaluates current trends in assessment and explores the benefits and limitations associated with the various forms of assessment. It addresses some of the key questions surrounding assessment, namely: why do we assess, what should we assess and who should assess? It also highlights the positive role of feedback and how it supports and facilitates learning. Finally, it explores assessment of learning as opposed to assessment for learning.

\section{Overview of Assessment}

Assessment is a fundamental component of both learning and teaching as it frames what students learn and their certification (Norcini JJ, 2003). Broadly speaking, assessment refers to the processes employed to make judgements about the achievements of students over a course of study (Harlen W, 2005). Universities are facing substantial challenges in meet the demands of 'Generation $\mathrm{Y}^{\prime}$ ' and the ever changing global context of medical education. Re-addressing assessment methods is a key component of this transformation of medical education. Over the past decade, huge efforts have been made to provide accurate and timely assessment of the competence of trainees (Leung WC, 2002). As the students of today are more inclined to question and challenge grades, there is a growing emphasis on ensuring that assessment methods are reliable, valid and able to sustain legal scrutiny (Leung WC, 2002). 
In educational practice, assessment methods can generally be classified as either formative i.e. enhances learning or summative i.e. for grades. Let us take a closer look at the benefits and limitations associated with each form of evaluation.

\section{Why do we assess our students?}

Before one can appropriately choose a summative or formative assessment method, there are key questions that should be answered. Firstly, why do we assess our students? Are we interested in what outcomes a student has met or how a student can better meet the desired outcomes? Historically, summative assessments were designed to provide professional self-regulation and accountability for the university (Leung WC, 2000). In contrast, formative assessments are intended to guide the learning process with a focus on providing feedback for the students. Key differentiating factors between the two approaches are the difference in time required to undertake the assessment process and the provision of comprehensive feedback.

Traditionally in undergraduate medical education, the focus was on summative assessment with one exam at the end of the year worth $100 \%$. However, some universities are adopting a continuous assessment approach with an assignment after each module. Although, the formative assessment approach embodies a more desirable ethos of assessment for learning, it is evident that it requires a substantial amount of time and a commitment from staff to provide timely and detailed feedback. However, it is this valuable feedback that makes the learning encounter engaging and worthwhile.

To help us appreciate the pivotal role of assessment in medical education, Epstein condensed his thoughts on the function of assessment into three goals: to optimise the capabilities of all learners, to protect the public by identifying incompetent physicians and to provide a basis for choosing applicants for advanced training (Friedman BDM, 2000). Although most universities would agree with the above in theory, a dichotomy frequently arises between what a university recognises as the optimal way of assessing students i.e. for learning, versus the practicalities of providing sustainable cost effective assessments (Kearney S, 2013).

\section{What are we trying to assess?}

Secondly, we must ask ourselves what are we trying to assess? Unfortunately, it is not possible to assess every educational outcome so how do we choose what outcomes to evaluate? Ideally we want to assess overall professional competence, however, as competence had been defined by Hundert using six interrelated domains, it is clear that some endpoints lend themselves more easily to assessment than others. This proposed model incorporates medical knowledge, technical skill, clinical reasoning, professionalism, communication skills and reflection (ACGME Outcome Project, 2000). As we can see from this model, knowledge and skills are far easier to assess that attitudes or professionalism (Epstein R and Hundert E, 2002). Traditionally in Medicine, softer skills such as communication were not emphasised or formally assessed. However, in recent years doctor's communications skills, or lack of, have accounted for the most common complaint to the Medical Council (Medical Council Annual Report, 2013). This has prompted many post graduate professional training bodies to teach and incorporate communication stations into post graduate exams.

Ideally, assessment of competence should provide insight into actual performance in the clinical setting as well as the capacity to adapt to change and generate new knowledge (Fraser SW, Greenhalgh T, 2001). This ideology has been reflected in postgraduate Medical training whereby many training bodies have introduced Mini Case Based Discussion (Mini-Cx) and Directly Observed Practical Skill (DOPS) to their routine evaluations, in a bid to reflect the complexity of real life medical scenarios. This practice represents a welcomed shift from the traditional approach to assessment and learning to the ideals of critical thinking and autonomy in medical education (Brint S, Cantwell AM and Hanneman RA, 2008).

\section{Who should assess students?}

Thirdly, one should consider who should assess students? In traditional forms of assessment the control rests with the lecturer (ACGME Outcome Project, 2000). However, there is a move towards multisource assessment, incorporating self and peer assessment, so that deeper and more authentic learning can occur (Speyer R, Pilz W, Van Der Krus J et al, 2011). Boud has long been an advocate of self-assessment as it fosters reflection and revision, leading to a more desirable learning outcome through collaboration and a mutual understanding of expectations (Boud D, Cohen R and Sampson J, 1999) (Speyer R, Pilz W, Van Der Krus J et al, 2011). It is imperative that students develop the capacity to make judgements about their own work and that of others in order to become effective continuing learners and practitioners (Boud D, 2010). 
In the past, universities did not tend to utilise self-assessment in undergraduate medical education but it can be rewarding for students as it gives them a framework, which they can bring into their everyday practice. When one considers why this method of assessment might not have been introduced, perhaps it was felt that the intense competition amongst students would lead to inflation in self-assessment grades. However, most of the data surrounding this method of assessment has shown a high correlation between self and teacher ratings (Hafner J and Hafner P, 2003).

Peer assessment has also been demonstrated to be an effective educational intervention (Boud $\mathrm{D}$, Cohen $\mathrm{R}$ and Sampson J, 1999). This has mainly been attributed to the fact that time on a task promotes learning, even if it's not grade bearing (Liu, N. and Carless, D, 2006). Recent studies have shown that when trainees receive thoughtful ratings and comments by peers in a timely manner, they find the process powerful, insightful and instructive (Norcini JJ, 2003). Although many students are initially sceptical about it as they tend to question the credentials of their peers, it can be a very worthwhile process. Importantly, a key part of the process is the support from a lecturer or supervisor to help guide feedback and to reflect on reports.

Furthermore, this form of assessment depends on trust and it is very helpful mid-way through a course when a group knows each other well and has established relationships. Otherwise, it has potential to be undermining, destructive and divisive (Lurie SJ, Nofziger AC, Meldrum S et al, 2006). In addition, peer assessment has been shown to be consistent from year to year regardless of the way assessors are selected (Lurie S, Lambert D, Grady Weliky TA, 2007). This inclusive multisource approach to assessment where a flexible range of assessment modes are made available to students, helps address the diverse needs of a modern day class and to engage students from all backgrounds (Lurie S, Lambert D, Grady Weliky TA, 2007).

\section{Assessment of learning and assessment for learning}

As touched on previously, assessment can broadly be categorised as either summative or formative. Following on from this we can also discuss assessment in terms of whether we are carrying out assessment of learning or for learning. The traditional summative form of assessment (Figure 1) can work well for the early medical years when core knowledge is being assessed. However, it can be lacking in the latter years when one is trying to nurture the critical thinking skills necessary for life as a Doctor. Many universities are incorporating more formative practices such as reflective portfolios, self and peer assessment, mini-cx and OSCE stations to the later medical years and a spreading assessment over all terms as opposed to the traditional end of a year exam. By doing so, the focus shifts from wrote learning to high quality integrated learning, which is far more engaging.
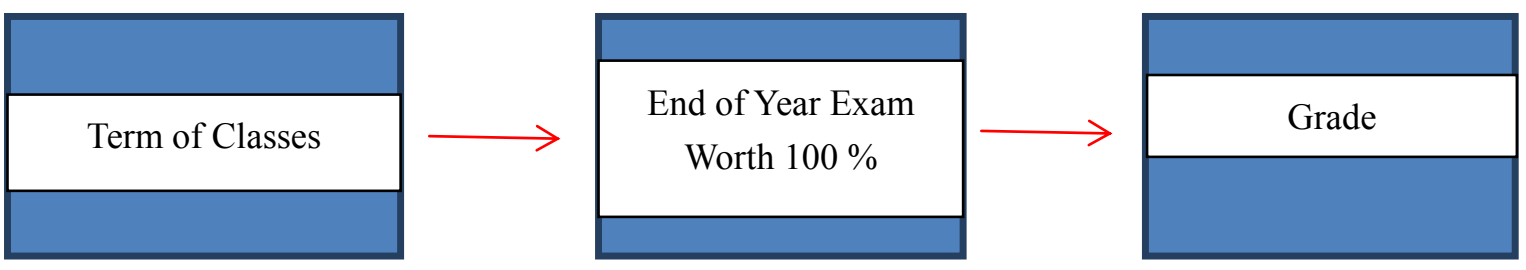

Figure 1. Summative Undergraduate Education

However, the pragmatics of putting this into effect are exceptionally challenging due to the lack of sufficient clinician and patient numbers in comparison to the sprawling class sizes. Many undergraduate medical classes have increased dramatically in size in recent years. For example, an average class size now consists of approximately 200 students. Conversely, there may be only approximately 30-40 medical clinicians that agree to teach one hour per week. One quickly begins to see the appeal of complimentary forms of assessment such as online modules and peer-assessment!

Although modern formative assessment methods are more time consuming, as they demand a sustained engagement with a focus on feedback, the crucial advantage is that students are aware of their performance and standard at regular intervals and receive guidance as to how to improve. Similarly, MCQ papers do not necessarily foster deeper learning as research has shown that unless students are told the correct answer straight away then they can learn the incorrect answer (Dawson P.). This is an important factor to bear in mind when constructing assessments. 
There is a growing appreciation of the changing needs of 'Generation Y'. Students are far more verbal about what they want from their education i.e. more bedside teaching as opposed to didactic lectures. They expect to be engaged and demand a sustained commitment from the teaching staff. Simple changes such as introducing a peer assessment component to the end of each bedside tutorial can have a positive impact. This method of teaching helps educators move closer to what is viewed by some as a more optimal form of assessment (Figure 2).

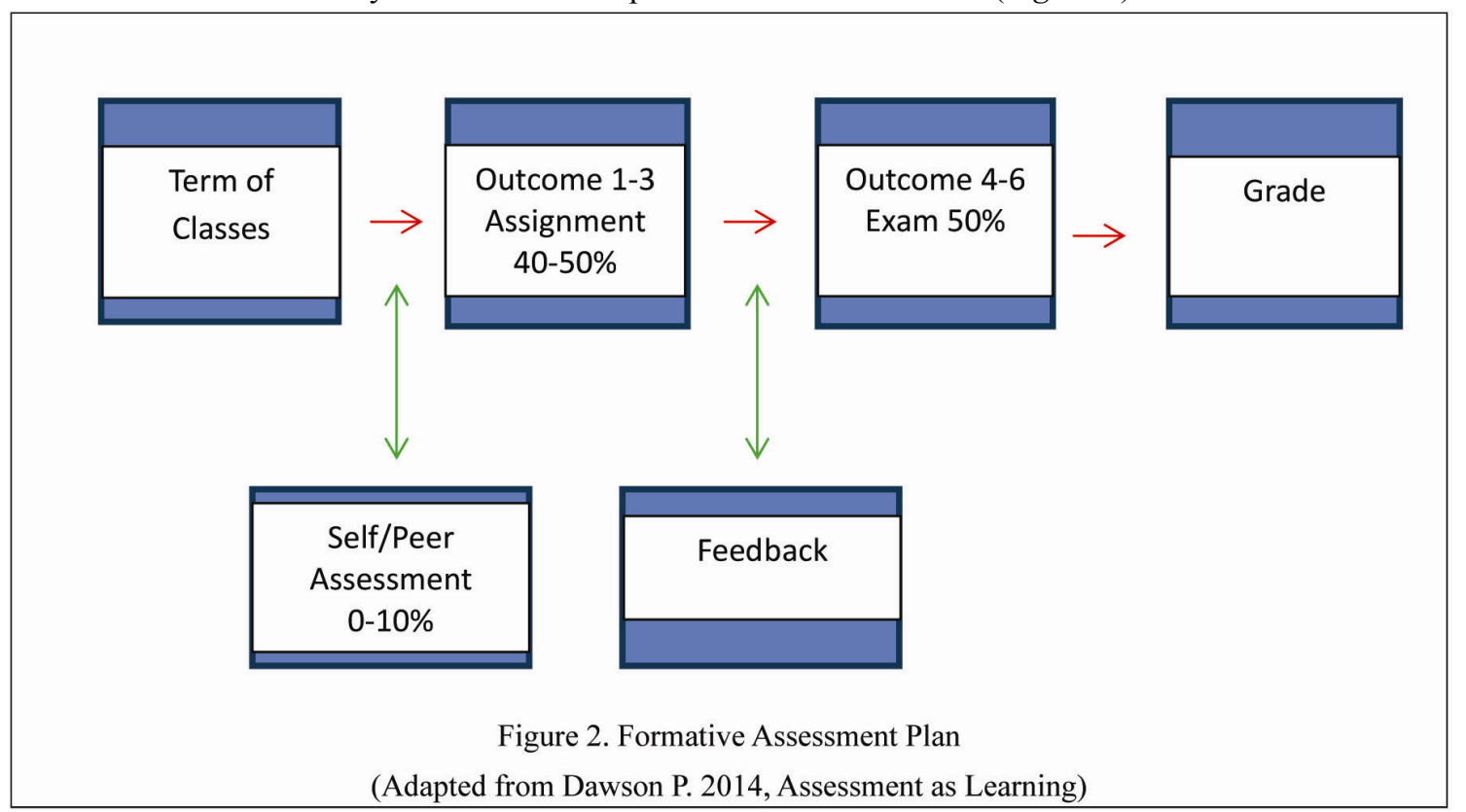

In addition, one can incorporated more interactive components into lectures in the form of polls using mobile phones as voting instruments and group exercises that actively involve the class. By doing so, educators can put Biggs's theory on student engagement into play (Biggs J, 1999) (Figure 3). By actively involving students in teaching, lessons become more engaging and the gap between the academic and the non- academic student can be approximated.

High level engagement

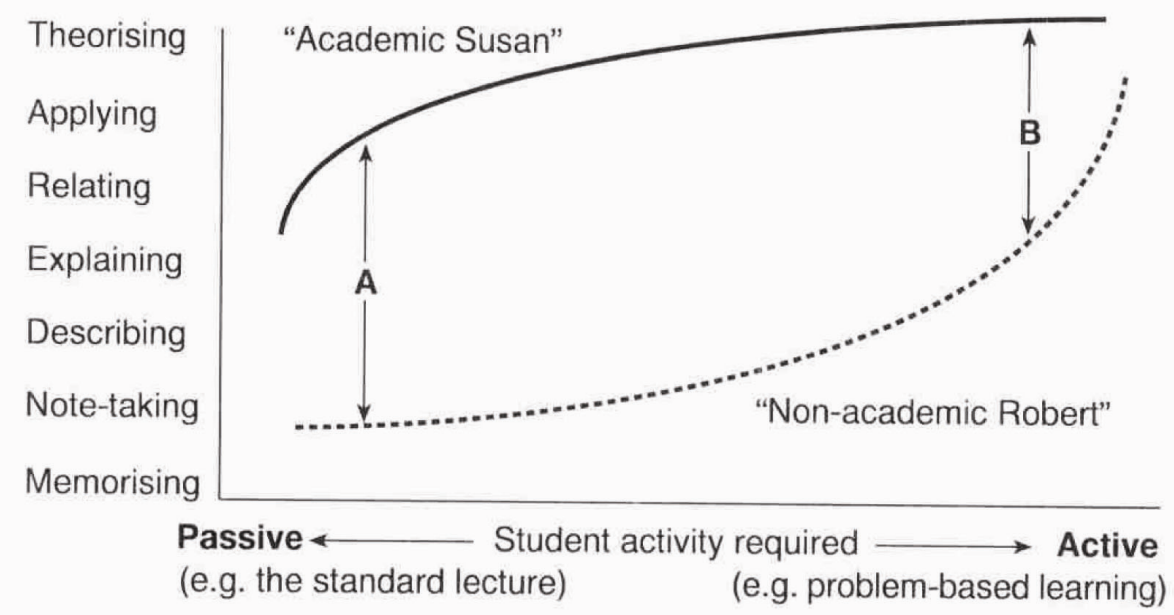

Low level engagement

Teaching method

Figure 3. Biggs J 1999. What the student does: teaching for enhanced learning. Higher education research and development 1999; vol 18:1. 
Furthermore, it is imperative that we are mindful of blueprinting and constructive alignment so that there is congruence between the subject matter delivered during lectures/tutorials, competencies expected to be acquired by the student and the items that appear on the exam (Bridge DP, Musial J, Frank R et al, 2003).

Simple changes as outlined above tend to be well received by the student body and it is encouraging for educators to see such a positive response to small changes. After all, our students are our partners in the learning process and our assessment methods should have at their core, practices that support learning and assist students in becoming better learners (Black P, Harrison C, Lee B et al, 2002) (Bridge DP, Musial J, Frank R et al, 2003).

\section{Conclusion}

Assessment is a central feature of teaching and the curriculum. It one of the most significant influences on a student's experience of higher education and improving assessment has a huge impact on the quality of learning (Liu, N. and Carless, D, 2006). Ideally we want to enhance a student's capacity for learning and engagement with the curriculum (ACGME Outcome Project, 2000). However, this doesn't always happen in practice as it is heavily dependent on the form of assessment used and whether or not timely comprehensive feedback is given.

It is evident that well designed formative assessment can focus students on effective learning and divert them away from summative assessment, which focuses attention on grades and reproductive thinking (Liu, N. and Carless, D, 2006). Whether one decides to utilise summative or formative assessment methods, both methods of assessment are useful when applied in the correct setting and at an appropriate stage of learning.

It is apparent that assessment is the gatekeeper of higher learning and we need to embrace new methods of assessment in order to meet the expectations and challenges associated with 'Generation Y' and globalisation. Novel assessment methods such as self and peer assessment are growing in popularity. Students who participate in these forms of assessment may initially feel that it is challenging but worthwhile overall, as it helps to develop their critical thinking skills (Bloxham S and West A, 2004). Incorporating complimentary assessment components could benefit student's learning without sacrificing the integrity of the course.

The discussion around assessment in this paper raises many questions. Namely, how much power will the lecturer have to relinquish in the future to facilitate a more student centred approach with diverse assessment methods? Furthermore, will graduates who have been exposed to multisource assessment be more prepared for the $21^{\text {st }}$ workplace? Continued research is needed into this area and it is clear that assessment will remain at a central position in the literature surrounding medical education. After all...

'Students can, with difficulty, escape from the effect of poor teaching. However, they cannot (if they want to graduate) escape the effects of poor assessment (Boud D, 1998).'

Boud D 1998.

\section{References}

ACGME Outcome Project. (2000). Accreditation Council for Graduate Medical Education Wed site. www.acgme.org.

Biggs J. (1999). What the student does: teaching for enhanced learning. Higher Education Research and Development 18:1. http://dx.doi.org/10.1080/0729436990180105

Black P, Harrison C, Lee B et al. (2002). Working inside the black box: assessment for learning in the classroom. London: Department of Education and Professional Studies, Kings College.

Bloxham S and West A. (2004). Understanding the rules of the game: Making peer assessment as a medium for assessing students' conceptions of assessment. Assessment \& Evaluation in Higher Education 29, no 6: 721-33. http://dx.doi.org/10.1080/0260293042000227254

Boud D, Cohen R \& Sampson J. (1999). Peer learning and assessment. Assessment and Evaluation in Higher Education 24, no 4: 413-26. http://dx.doi.org/10.1080/0260293990240405

Boud D. (1998). Assessment and learning- unlearning bad habits of assessment. Effective assessment at university conference, Queensland, Nov, page 1.

Boud D. (2010). Assessment 2020: seven propositions for assessment reform in higher education. Sydney: Australian learning and teaching council, page 1-4.

Bridge DP, Musial J, Frank R et al. (2003). Measurement practices: methods for developing content valid student examinations. Med Teach 25: 414-421. http://dx.doi.org/10.1080/0142159031000100337 
Brint S, Cantwell AM \& Hanneman RA. (2008). The two cultures of undergraduate academic engagement. Research in Higher Education 49:383-402. http://dx.doi.org/10.1007/s11162-008-9090-y

Dawson P. Assessment as learning. https://www.youtube.com/watch?v=njgyYUNkyAs

Epstein R \& Hundert E. (2002). Defining and assessing professional competence. JAMA 287 (2): 226-235. http://dx.doi.org/10.1001/jama.287.2.226

Epstein R (2007). Assessment is medical education. NEJM 356:387-96. http://dx.doi.org/10.1056/NEJMra054784

Fraser SW, Greenhalgh T. (2001). Coping with complexity: educating for capability. BMJ 323:799-803. http://dx.doi.org/10.1136/bmj.323.7316.799

Friedman BDM. (2000). The role of assessment in expanding professional horizons. Med Teach 22:472-7. http://dx.doi.org/10.1080/01421590050110731

Hafner J \& Hafner P. (2003). Quantitative analysis of the rubric as an assessment tool: an empirical study of student peer group rating. International Journal of Science Education 25, no 12: 1509-28. http://dx.doi.org/10.1080/0950069022000038268

Harlen W. (2005). Teachers' summative practices and assessment for learning- tensions and synergies. The Curriculum Journal 16(2),207-223. http://dx.doi.org/10.1080/09585170500136093

Kearney S. (2013). Improving engagement: the use of authentic self and peer assessment for learning to enhance the student experience. Assessment and evaluation in higher education; 38:7, 875- 891. http://dx.doi.org/10.1080/02602938.2012.751963

Leung WC. (2002). Competence based medical training: review. BMJ 325:693-6. http://dx.doi.org/10.1136/bmj.325.7366.693

Liu, N. \& Carless, D. (2006). Peer feedback: the learning element of peer assessment. Teaching in Higher Education, 11(3), pp.279-290. http://dx.doi.org/10.1080/13562510600680582

Lurie S, Lambert D, Grady Weliky TA. (2007). Relationship between dean's letter rankings, peer assessment during medical school and ratings by internship directors. Journal of General Internal Medicine Jan; 22(1): 13-16.

Lurie SJ, Nofziger AC, Meldrum S et al. (2006). Temporal and group related trends in peer assessment amongst medical students. Med Educ 40: 840-7. http://dx.doi.org/10.1111/j.1365-2929.2006.02540.x

Medical Council Annual Report.

(2013). http://www.medicalcouncil.ie/News-anPublications/Reports/annual-report1.pdf

Norcini JJ. (2003). Peer assessment of competence. Med Educ 37:539-43. http://dx.doi.org/10.1046/j.1365-2923.2003.01536.x

Speyer R, Pilz W, Van Der Krus J et al. (2011). Realibility and validity of student peer assessment in medical education: a systematic review. Medical Teacher 33: e 572-e585.

Wormald BW, Schoeman S, Somasunderman A et al. (2009). Assessment drives learning: an unavoidable truth? Anat Sci Educ Oct; 2 (5):199-204. 